\title{
Respiratory health of young shipyard welders and other tradesmen studied cross sectionally and longitudinally
}

\author{
D J Chinn, J E Cotes, F M El Gamal, J F Wollaston
}

\begin{abstract}
Objective-To assess the effectiveness of current measures for protecting shipyard welders and caulker/burners (WCBs) from the respiratory effects of fumes.

Methods-Shipyard tradesmen born after 1953 (cohort 1), and 181 older men, subjects of a previous study (cohort 2 ), were assessed, then followed up after an average interval of 6.7 years. The respiratory associations with shipyard trades were assessed cross sectionally and longitudinally and an estimate made of the likely effects of selection bias. Cohort 1 comprised $90 \%$ of the 462 eligible WCBs and 239 other tradesmen; there were 31 exclusions. At follow up 139 of 146 men still in the shipyard and $43 \%$ of those who had left were reassessed. The lapses were mainly due to migration. All members of cohort 2 were followed up for respiratory symptoms (from MRC questionnaire), were recorded, and indices reflecting all aspects of lung function were measured.
\end{abstract} Results-At the initial assessment and independent of smoking, trade as a WCB was associated with increased prevalences of chronic cough, phlegm, and wheeze, a reduced transfer factor, and an enhanced age related deterioration in peak expiratory flow (measured cross sectionally). Continued work as a WCB was associated with enhanced deterioration in lung function despite some amelioration of respiratory symptoms; the deterioration was influenced by whether or not exhaust ventilation had been used for every weld. The effects of fume on forced expiratory volume, flow-volume curvilinearity, mean transit time, and moment ratio were independent of and at least as large as those due to smoking. Enhanced deterioration in peak expiratory flow was confined to WCBs who smoked. These effects of trade, but not those of smoking, were nearly independent of atopy.

Conclusion-In WCBs the working practices over the period of the study did not prevent the development of mild respiratory impairment. In WCBs who used exhaust ventilation at all times, the impairment seemed to reverse by discontinuation of exposure. Thus existing hygiene measures should be applied rigorously. The biological effectiveness of these and any other necessary supple- mentary measures should be assessed by long term monitoring of forced expiratory volume and peak expiratory flow.

(Occup Environ Med 1995;52:33-42)

Keywords: welders; shipyard; lung function; longitudinal studies

Shipyard welders and caulker/burners (WCBs) in north eastern England have been reported to have an increased morbidity and mortality from pneumonia and chronic bronchitis and diminished lung function compared with other shipyard tradesmen. ${ }^{3}$ The changes in lung function were particularly evident in welders who were also smokers or had an atopic constitution. ${ }^{4}$ Most of the subjects for these studies had worked in the shipyards before the introduction of exhaust ventilation in the early 1970 s and probably had been exposed to high concentrations of fumes. Our study was directed at finding out if current hygiene measures adequately protected young men (mean age 23 years), most of whom began work after 1973 when local fume extraction became widely available. The study was planned as a longitudinal one but due to large scale redundancies many workers left the industry after the first examination and were not available for follow up. This could have biased the population that remained. The extent of any initial bias was assessed by comparing the findings at first examination for workers who were reassessed, with those who were lost to follow up. A detailed cross sectional analysis of all the initial data was also undertaken. The results showed that the hygiene measures, though they usually met the current hygiene standard, did not protect fully against the respiratory effects of fumes from welding and burning: however, in the caulker/burners and those welders who reported that they always used their extraction hoses the impairment in lung function seemed to completely reverse when exposure was discontinued.

\section{Methods}

SUBJECTS AND TIMETABLE

The 234 welders and 228 caulker/burners employed at four shipyards on the Tyne who were born after 1953 were identified from a list of employees dated 4 April 1980 and supplied by the management. With the 
agreement of the Amalgamated Society of Boilermakers, the men were approached and invited to participate in the study, which was explained to them. The investigation had the approval of the local ethics committee.

Examinations were conducted between August 1980 and September 1984 by which time 222 welders and 194 caulker/burners had been seen; they comprised $95 \%$ and $85 \%$ of the defined population.

Electricians identified from the works list were chosen as the control group, but volunteers from other trades were also accepted; 239 men were seen. Subsequently three welders and four caulker/burners were excluded because their results were of poor technical quality or because of incomplete data or unrelated medical conditions. A clinical history of asthma led to the exclusion of a further 24 men (six welders, six caulker/burners, and 12 other tradesmen). The results for the remaining 624 men (designated cohort 1) were included in the cross sectional analysis. The follow up study started in 1987 and was completed in 1991 .

Exactly comparable longitudinal information to that obtained for cohort 1 was also available for 181 older men (cohort 2 , initial mean age $41 \cdot 7$, range $29 \cdot 4-47 \cdot 4$ ). These men, who were the subjects of an earlier cross sectional study, ${ }^{5}$ had started work before the introduction of exhaust ventilation and related hygiene measures. Their results, which were not included in the main analysis, contributed to the inquiries into the possible relevence of atopy and the effectiveness of exhaust ventilation, once it had been introduced.

\section{INFORMATION THAT WAS OBTAINED}

At each attendance the MRC questionnaire on respiratory symptoms (1976) with additional questions about employment, exhaust ventilation, and habitual leisure time activity was completed. (Questionnaire obtainable on request from MRC, 20 Park Crescent, London W1N 4AL.) Also in the second part of the initial survey the amount of current cough was assessed quantitatively on a 10 point scale by the method of Field. ${ }^{6}$ Atopy was determined from the response to skin prick tests performed at the second examination except for 44 men who reported a history of hay fever on both attendances: 20 of these men were skin tested and found to be positive so the remaining 24 were accepted as atopic without additional evidence. The skin tests were to mixed grasses, house dust mite, Aspergillus fumigatus, cat fur, and normal saline. A wheal of diameter $>2 \mathrm{~mm}$ in response to antigen but not saline was considered positive.

Anthropometric measurements included stature, body mass, fat free mass and percentage fat; these quantities were measured respectively with a stadiometer (Harpenden), beam balance (Avery), and skin calipers (Harpenden). The equipment was calibrated and used in the manner recommended for the International Biological Programme. ${ }^{7}$ The fat free mass and percentage fat were calculated from body mass and four skinfold thicknesses by the method of Durnin and Rahaman. ${ }^{8}$

Dynamic spirometry was performed in quintuplicate with a dry bellows digital spirometer (McDermott); the volume-time information was encoded in real time on cassette tape as the number of $10 \mathrm{ml}$ increments of volume expired every $10 \mathrm{~ms} .^{9}$ After each blow the flow-volume (F/V) curve was plotted and five spirographic indices, as calculated by the spirometer's microprocessor, were recorded. The indices were forced expiratory volume $\left(\mathrm{FEV}_{1}\right)$, forced vital capacity (FVC), peak expiratory flow (PEF), and maximal flows when $50 \%$ and $25 \%$ of FVC remained to be expired $\left(\mathrm{MEF}_{50 \% \mathrm{FvC}}\right.$ and $\mathrm{MEF}_{25 \% \mathrm{FvC}}$ ). For these indices the highest of the first three technically satisfactory expirations was accepted for analysis. The selection criteria were that the FVC was within $5 \%$ of the maximum, the F/V curves were of similar overall shape, and the PEF was within $10 \%$ of the maximal observed value. ${ }^{10}$

For the microprocessor calculation of $\mathrm{FEV}_{1}$ the expiration was considered to have started when 0.11 had been expired. Subsequently, the tape records were reprocessed with a portable computer (Amstrad): the F/V curves were replotted and the start of forced expiration was redefined by back extrapolation of the steepest part of the volume-time curve to zero time. The indices were then recalculated and additional indices were derived, including the forced expiratory time up to expiration of $99 \%$ of FVC (FET), the maximal midexpiratory flow (MMEF), the average rate of flow during the expiration of the last part of the FVC $\left(\mathrm{FEF}_{75} 85 \%\right)$, the area under the $F / V$ curve ( $F / V$ area), and the area ratio for the curve between the peak and the end of expiration. The ratio was that of the total area under this part of the curve to that of the triangle formed by replacing the descending limb of the curve by a straight line. The index reflected the curvilinearity of the F/V curve. Also, the data were submitted to moments analysis to obtain the mean transit time (MTT) and its derivatives. These included the moment ratio (MR). The indices were obtained from F/V curves truncated by volume after the expiration of $75 \%, 90 \%$, and $99 \%$ of the FVC. The method is described elsewhere. ${ }^{\prime \prime}$

The transfer factor of the lung for carbon monoxide ( $\mathrm{Tl}$ ') was measured in duplicate by the single breath method (P K Morgan). The alveolar volume used in the calculation (VA') was that obtained from the dilution in the lung of helium contained in the test gas mixture. Gas analysis for carbon monoxide was by infrared absorption and for helium by katharometry. The equipment was calibrated and the results calculated by standard methods. ${ }^{12}$ Also, on most workers the total lung capacity (TLC) and the subdivisions functional residual capacity (FRC) and residual volume (RV), were measured by the closed circuit helium dilution method. ${ }^{13}$ In these subjects the airway obstruction index was 
calculated from $\mathrm{FEV}_{1} \%, \mathrm{RV} \%$, and $V \mathrm{~A}^{\prime} / V \mathrm{~A} .{ }^{14}$ Maximal respiratory pressures sustainable for one second by inspiration from functional residual capacity (MIPFRC) and expiration from total lung capacity (MEP) were measured in triplicate with a closed brass tube (dead space $110 \mathrm{ml}$ ), differential pressure transducer linear to $30 \mathrm{kPa}$ (mercury) and $\mathrm{Y} / \mathrm{t}$ recorder (J J Instruments). The subject wore a nose clip. For the measurement of expiratory pressure a capillary leak was used to avoid error due to contraction of the muscles of the cheeks. For the measurement of inspiratory pressure the connections to the transducer were reversed to avoid any error due to the calibration characteristics of the two sides not being identical. The highest value was recorded. The calibration of the pressure transducer was checked daily and monitored regularly during use.

In 181 workers from cohort 1 (and also those in cohort 2) the slope of the alveolar plateau for nitrogen recorded during a slow expiration after a single slow VC breath of $100 \%$ oxygen, the closing volume, and the closing capacity were measured with HewlettPackard equipment. This comprised a nitrogen analyser (model 47302A), Fleisch No 1 pneumotachograph and flow transducer (model 47304A), XYt printer (model $9841 \mathrm{~A}$ ), and desk top computer (model 9825). The slope of phase III was taken from when $30 \%$ of VC had been expired to the onset of phase IV by the criteria of Craven $e t$ $a l .{ }^{15}$ The measurements conformed to the recommendations of the National Heart and Lung Institute ${ }^{16}$ on flow rates $\left(<0.51 \mathrm{~s}^{-1}\right)$, consistency of all the VC manoeuvres $( \pm 5 \%)$, and absence of step changes in nitrogen concentration.

ESTIMATES OF EXPOSURE

The WCBs supplied information on the proportions of time they had spent in confined and semiconfined spaces. The resulting index of exposure did not make a significant contribution to the analysis. The welders also reported on their use of exhaust ventilation; the information was used to subdivide welders into those who did or did not use exhaust ventilation $100 \%$ of the time. This categorical variable was included in the final analysis. Also, views were elicited from welders about the effectiveness of exhaust ventilation.

Routine environmental monitoring was carried out on air samples taken from behind a man's visor. The sample periods were two to four hours in duration and the samples were analysed for respirable particulates, oxides of nitrogen, carbon monoxide, carbon dioxide, and sometimes for ozone. The hygiene standard for welding fume, expressed as total respirable particulate, was $5 \mathrm{mg} \mathrm{m^{-3 }}$ averaged over an eight hour shift. The standards for the other gases were for carbon monoxide 50 ppm, carbon dioxide 5000 ppm, nitric oxide $25 \mathrm{ppm}$, nitrogen dioxide $5 \mathrm{ppm}$, and ozone $0.1 \mathrm{ppm} .{ }^{17}$ Samples were taken independently of the present study and cross linkage was not possible.
ANALYSIS

For each test all the results were scrutinised for technical quality by one observer (DJC). The numerical values were checked again after entry into the computer (Amdahl). The multiple and logistic regression analyses were performed with the statistical package for the social sciences of the University of Michigan (SPSS, release 4.0). Data were analysed with linear terms except for some transit time indices that were normalised by earlier transformation to natural logarithms. Also, changes in $\mathrm{FEV}_{1}\left(\triangle \mathrm{FEV}_{1}\right)$ were reported with a proportional, as well as a linear model (units respectively $\Delta \mathrm{x} \sqrt{\mathrm{x}} \mathrm{y}^{-1}$ and $\mathrm{ml} \mathrm{y}^{-1}$ ).

For the longitudinal analyses, age (A, y) was the mean over the period of follow up. Change in stature $\left(\Delta \mathrm{St}, \mathrm{m} \mathrm{y}^{-1}\right)$ was included because most of the men were still growing on entry into the study. Body mass and fat free mass (FFM) were expressed as body mass index (BMI) and FFM.St ${ }^{-2}$ (in the units $\mathrm{kg}$ $\mathrm{m}^{-2}$ ), as these indices were independent of stature. Initially, $\triangle F F M . \mathrm{St}^{-2}$ was used $\xi_{\text {in }}$ association with $\Delta \%$ fat in preference to $\Delta \mathrm{BMI}$ because in the cross sectional analyses, the component terms accounted for more of the explained variance than BMI. For the longitudinal analysis, however, BMI proved to be equally informative.

Smoking, depending on circumstances, was treated as either a categorical or continuous variable; the continuous variable was based on the number of cigarettes smoked a day at the time of the follow up survey. For the cross sectional analysis, smokers were defined as current smokers plus those who had discontinued smoking within the preceeding six months. Non-smokers had never smoked as much as one cigarette a day for one year. Exsmokers were excluded from the cross sectional analysis. For the longitudinal analysis ex-smokers were reclassified as smoker or non-smoker depending on whether or not they had ever smoked during the period of follow up.

Trade $(T)$ was a categorical variable where 1 identified a man as having been a WCB and 0 as an electrician or other tradesman. For most analyses, WCBs were treated together because, although their occupational exposures differed, their scores for respiratory symptoms, lung function, and change in lung function over the period of follow up were found to be similar; this was also the case in the previous longitudinal study. ${ }^{4}$ Shipyard (SY) was used in the longitudinal analysis to identify men who either continued to work in one of the original shipyards or had left but had practised their trade in another shipyard for at least $85 \%$ of the available time. The WCBs who continued to work in a shipyard were identified by the interaction term T.SY; this term was accepted as making a significant contribution to the variance explained by the regression only in the presence of the constituent terms $T$ and $S Y$. The equation that was reported was then that for all terms that made a significant contribution to the variance explained by the regression. 
In the multiple regression analyses, terms were admitted in a stepwise fashion in the order that reflected their contribution to the explained variance. The $5 \%$ level of probability was accepted as significant.

\section{Results \\ FINDINGS AT INITIAL ATTENDANCE (CROSS SECTIONAL ANALYSIS) \\ Description of subjects}

Table 1 shows the mean age and other details of the 624 men included in the cross sectional analysis. The group included 294 lifetime non-smokers and 261 current smokers whose average tobacco consumption was $18 \cdot 6$ (range $0 \cdot 1-58 \cdot 6) \mathrm{g}$ a day. Compared with the lifetime non-smokers, a higher proportion of the smokers were WCBs $(P<0.01)$. The WCBs were significantly older than the other tradesmen (mean ages respectively 23.5 and $22.3, \mathrm{P}$ $<0.01$ ). The proportion of men that reported respiratory symptoms was related to smoking (table 2) and, for some symptoms, to age. Among the non-smokers the prevalence of wheeze, the grade of current cough (after adjusting for age), and a history of producing phlegm (but not of cough and phlegm) for more than three months in the year were related to the trade of WCB. Among the smokers the prevalence of chronic productive cough was related to trade (table $3(A)$ ). The effects of trade were independent of the amount smoked (table 3(B)).

Table 1 Values for selected indices that describe 624 subjects of the cross sectional study and the changes/year in the 346 subjects followed up longitudinally

\begin{tabular}{|c|c|c|}
\hline & \multirow{2}{*}{$\frac{\text { Cross sectional }}{\text { Mean (range) }}$} & \multirow{2}{*}{$\frac{\text { Longitudinal }}{\text { Mean (SD) }}$} \\
\hline & & \\
\hline Age $(A, y)$ & $23 \cdot 1(17 \cdot 3-30 \cdot 5)$ & $-(-)$ \\
\hline Stature $(\mathrm{St}, \mathrm{m})$ & $1.74(1.57-1.94)$ & $0.0006(0.001)$ \\
\hline Body mass index (BMI, $\left.\mathrm{kg} \mathrm{m}^{2}\right)$ & $23.7(16.4-39.00)$ & $0.16(0.28)$ \\
\hline Body fat $(F, \%)$ & $16 \cdot 0(5 \cdot 8-33 \cdot 3)$ & $0.27(0.54)$ \\
\hline Fat free mass $/ \mathrm{St}^{2}$ (FFM.St. ${ }^{2}, \mathrm{~kg} \mathrm{~m}^{2}$ ) & $19 \cdot 8(14 \cdot 5-30 \cdot 1)$ & $0.06(0.18)$ \\
\hline Forced expiratory volume (FEV, 1$)$ & $4.39(1.91-6.14)$ & $-0.0111(0.035)$ \\
\hline Forced vital capacity (FVC, 1) & $5.38(3.56-7.42)$ & $0.0142(0.040)$ \\
\hline FEV $\%$ of FVC $($ FEV $\%)$ & $81.7(53.6-96.7)$ & $-0.422(0.44)$ \\
\hline Peak expiratory flow (PEF, $1 \mathrm{~s}^{-1}$ ) & $9.97(5 \cdot 0-15 \cdot 5)$ & $0.0351(0.136)$ \\
\hline Mean transit time (MTT $4:, \ldots, s$ ) & $0.61(0.32-1.81)$ & $0.0219(0.018)$ \\
\hline Moment ratio (MR & $1.49(1.22-1.92)$ & $0.0297(0.022)$ \\
\hline Total lung capacity (TLC, 1) & $6 \cdot 62 \star(4 \cdot 13-9 \cdot 53)$ & $0.01649(0.058)$ \\
\hline Expiratory vital capacity (EVC, l) & $5.42 \star(3.47-7.69)$ & $-0.0023(0.044)$ \\
\hline Inspiratory capacity (IC, 1 ) & $3 \cdot 38^{\star}(1 \cdot 75-5 \cdot 08)$ & $0.00985(0.063)$ \\
\hline Functional residual capacity (FRC, l) & $3 \cdot 24^{\star}(1 \cdot 36-5 \cdot 75)$ & $0.0066 \$(0.071)$ \\
\hline Residual volume $(\mathrm{RV}, \mathrm{l})$ & $1 \cdot 19^{\star}(0 \cdot 46-2 \cdot 41)$ & $0.0190 \$(0.040)$ \\
\hline Transfer factor ( $\mathrm{Tl}^{\prime}, \mathrm{m}$ mol min $\mathrm{kPa}$ ) & $12 \cdot 2(7 \cdot 3-18 \cdot 5)$ & $-0.1097(0.189)$ \\
\hline KCo(Tl'VVA', SI units) & $1.92(1.34-2 \cdot 77)$ & $-0.0209(0.027)$ \\
\hline $\begin{array}{l}\text { Maximal inspiratory pressure } \\
\text { (MIPFRC, } \mathrm{kPa} \text { ) }\end{array}$ & & \\
\hline $\begin{array}{l}\text { Closing volume (CV/VC, \%) } \\
\text { Clare }\end{array}$ & $\begin{array}{r}10 \cdot 89 \dagger(3 \cdot 4-20 \cdot 1) \\
9 \cdot 87 \ddagger(0.0-39 \cdot 0)\end{array}$ & $\begin{array}{r}-0.229(0.44) \\
0.28 \mid(0.72)\end{array}$ \\
\hline Nitrogen index $\left(\mathrm{N}_{2}\right.$ slope, $\left.\% \mathrm{~N}_{2} \mid{ }^{\prime}\right)$ & $0.69 \ddagger(0 \cdot 17-3 \cdot 62)$ & $0.0079 \|(0.050)$ \\
\hline
\end{tabular}

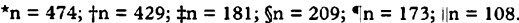

Table 2 Proportion of WCBs and prevalence of respiratory symptoms (\%) in relation to smoking

\begin{tabular}{|c|c|c|c|}
\hline & $\begin{array}{l}\text { Non-smokers } \\
(n=294)\end{array}$ & $\begin{array}{l}\text { Ex-smokers } \\
(n=69)\end{array}$ & $\begin{array}{l}\text { Smokers* } \\
(n=261)\end{array}$ \\
\hline $\begin{array}{l}\text { WCBs (\% of survey population) } \\
\text { Cough }(\mathrm{C})>3 / 12 \text { months } \\
\text { Phlegm }(\mathrm{P})>3 / 12 \text { months } \\
\mathrm{C}+\mathrm{P}>3 / 12 \text { months } \\
\text { Occasional wheeze } \\
\text { Regular wheeze }\end{array}$ & $\begin{array}{r}52 \cdot 4 \\
4 \cdot 1 \\
6 \cdot 8 \\
3 \cdot 1 \\
17 \cdot 7 \\
1 \cdot 4\end{array}$ & $\begin{array}{r}73 \cdot 9 \\
2 \cdot 9 \\
11 \cdot 6 \\
2 \cdot 9 \\
29 \cdot 0 \\
0\end{array}$ & $\begin{array}{l}73 \cdot 6 \\
24 \cdot 1 \\
28 \cdot 4 \\
18 \cdot 4 \\
35 \cdot 2 \\
11 \cdot 5\end{array}$ \\
\hline
\end{tabular}

*Smokers were significantly different from non-smokers (ex-smokers mainly formed an intermediate group).

†Symptoms from MRC questionnaire of respiratory symptoms.
Lung function at initial assessment

The mean lung function of the workers was that to be expected for healthy men ${ }^{13}$; however, the ranges were wide. This was due in part to the lungs of the younger men not having reached their adult size; hence total lung capacity and all its subdivisions except expiratory reserve volume were related positively to age.

Among the indices obtained by dynamic spirometry, PEF increased with age despite an age related decline in maximal respiratory pressures. All the other dynamic indices including the $\mathrm{FEV}_{1}$, the maximal flows $\mathrm{MEF}_{50 \% \mathrm{FVC}}$ and $\mathrm{MEF}_{25 \% \mathrm{FVC}}$, the transit time indices, and FET showed an age related deterioration. Similar changes were found in the closing volume and capacity, although not in the nitrogen slope. For the indices where the trend with age was towards deterioration this was in most instances enhanced by smoking.

Trade as a WCB was associated with increased curvilinearity of the $F / V$ curve ( $F / V$ area ratio reduced), an increase in expiratory reserve volume (and hence in functional fesidual capacity), and a reduction in transfer factor. Trade was also associated with an age related deterioration in PEF and in expiratory vital capacity. The effects of trade were independent of those of smoking except in the case of the mean transit time at $75 \%$ truncation $\left(\mathrm{MTT}_{75 \% \mathrm{FvC}}\right)$, which was increased in WCBs who smoked. The possibility that this result might have concealed very early changes in men with apparently normal lung function was assessed by repeating the regression analysis for the 510 men in whom the $\mathrm{FEV}_{1} \%$ was above the lower $90 \%$ confidence limit found for the asymptomatic non-smokers in the present population. In this subgroup, trade interacted with smoking (and in some instances with age) to increase the MTT at the other levels of truncation $\left(\mathrm{MTT}_{90 \% \mathrm{FvC}}\right.$ and $\mathrm{MTT}_{99 \% \mathrm{Fc}}$ ) as well.

The association between respiratory symptoms and lung function was assessed by repeating the multiple regression analysis after replacing the terms for smoking and trade with those for wheeze and chronic productive cough (CP $>3 / 12$ months). A history of wheeze was associated with significant deterioration in almost all the indices obtained by dynamic spirometry. A history of chronic productive cough affected only a few indices. In the case of $F E V_{1}$ and PEF the inclusion of respiratory symptoms increased the proportion of variance that was explained compared with that when smoking and trade were included (explained variances for $\mathrm{FEV}_{1}$ were with symptoms $38.4 \%$ and with smoking and trade $36.3 \%$; the corresponding figures for PEF were $17 \cdot 2 \%$ and $14.9 \%)$. The respiratory symptoms seemed not to affect the total lung capacity (and the subdivisions inspiratory VC, inspiratory capacity, and residual volume), the maximal respiratory pressures, transfer factor, and $\mathrm{KCO}$.

The proportion of atopy among the present workers was $41 \%$ and among cohort 2 it was $24 \%$. The possible role of atopic status was assessed by including this term in a further 
Table 3 Logistic regression analysis of respiratory symptoms in terms of trade and smoking: in (A) smoking is expressed as a categorical variable (yes or no), and in $(B)$ as a continuous variable ( $g / d a y)$

\begin{tabular}{|c|c|c|c|c|c|}
\hline \multirow[b]{3}{*}{ Symptom } & \multicolumn{4}{|c|}{ (A) Smokers and non-smokers $(n=555)$} & \multirow{3}{*}{$\frac{\text { (B) Smokers }(n=261)}{\text { Odds ratio for trade }}$} \\
\hline & \multirow{2}{*}{$\begin{array}{l}\text { Prevalence } \\
(\%)\end{array}$} & \multicolumn{3}{|l|}{ Odds ratio $(95 \% \mathrm{CI})$} & \\
\hline & & Smoking & Trade & Smoking $\times$ trade & \\
\hline $\begin{array}{l}\text { Cough }(\mathrm{C})>3 / 12 \text { months } \\
\text { Phlegm }(\mathrm{P})>3 / 12 \text { months } \\
\mathrm{C}+\mathrm{P}>3 / 12 \text { months } \\
\text { Wheeze } \\
\text { Cough score } \$(>3)\end{array}$ & $\begin{array}{l}13 \cdot 5 \\
16 \cdot 9 \\
10 \cdot 3 \\
32 \cdot 0 \dagger \\
33 \cdot 7\end{array}$ & $\begin{array}{l}2.65(1.00-7.01) \\
4.66^{\star}(2 \cdot 72-7.97) \\
3.02(1.04-8.78) \\
3.35^{\star}(2 \cdot 26-4.95) \\
3.32(1.67-6.64)\end{array}$ & $\begin{array}{l}\text { NS } \\
2 \cdot 85^{\star}(1 \cdot 57-5 \cdot 17) \\
\text { NS } \\
2 \cdot 28^{\star}(1 \cdot 48-3.52) \\
2 \cdot 59(1 \cdot 20-5 \cdot 57)\end{array}$ & $\begin{array}{l}3.65(1 \cdot 57-8 \cdot 46) \\
\text { NS } \\
2.94(1 \cdot 19-7 \cdot 26) \\
\text { NS } \\
\text { NS }\end{array}$ & $\begin{array}{l}3.52(1.49-8.36) \\
2.16(1.07-4.36) \\
2.77(1.10-6.96) \\
1.83^{\star}(1.01-3.32) \\
\text { NS }\end{array}$ \\
\hline
\end{tabular}

multiple regression analysis. Atopy did not influence the effects of trade, but atopic smokers had lower PEF and a higher KCO than the other subjects.

\section{RESULTS FOR WORKERS WHO WERE FOLLOWED UP \\ Description}

The average interval between the initial assessment in the shipyard and the follow up was 6.7 years. In the intervening period 478 of the men had left the yard; in most instances this was due to their having been made redundant. The men who left included significantly more WCBs $(80.6 \%)$ than other tradesmen (69.6\%). The leavers had also reported significantly more chronic phlegm (18\%) and more wheeze $(33.9 \%)$ at their initial examination compared with those who remained $(11 \%$ of whom reported phlegm and $24 \cdot 7 \%$ wheeze). Despite these differences the leavers did not differ from the rest with respect to age, bodily dimensions, or initial lung function standardised for age, smoking, and the anthropometric variables.

One hundred and forty six men were still working in the shipyard at the time of follow up and $139(95 \%)$ of them were reassessed: the seven lapses were due to refusal. Of the 478 men who had left the yard 207 (43\%) were reassessed. The 271 lapses were mainly due to moving out of the area or to loss of contact despite repeated attempts ( $246 \mathrm{men}$ ). Two men had died and there were 23 refusals. The lapses from the initial population included a significantly higher proportion of the WCBs than of the other tradesmen. The lapses as a group and the WCB lapses on their own were significantly younger (by on average 1.7 years), comprised significantly more smokers, and had initially reported significantly more respiratory symptoms than those who were reassessed. The initial lung function of the lapses and of the men who were

Table 4 Factors associated with development of respiratory symptoms during follow up

\begin{tabular}{lll}
\hline & \multicolumn{2}{l}{ Odds ratio $(95 \%$ CI $)$} \\
\cline { 2 - 3 } Symptom & Smoking & Trade as WCB \\
\hline Chronic cough $(\mathrm{C})>3 / 12$ months & $5 \cdot 18(2 \cdot 21-12 \cdot 10)$ & NS \\
Chronic phlegm $(\mathrm{P})>3 / 12$ months & $\mathrm{NS}$ & $2 \cdot 83(1 \cdot 24-6 \cdot 42)$ \\
$\mathrm{C}+\mathrm{P}>3 / 12$ months & $3 \cdot 78(1 \cdot 58-9 \cdot 06)$ & $\mathrm{NS}$ \\
Wheeze (occasional or regular) & $4 \cdot 24(2 \cdot 32-7 \cdot 74)$ & $\mathrm{NS}$ \\
\hline
\end{tabular}

reassessed was similar apart from the transfer factor and some transit time indices, which were significantly better in those who were reassessed. The differences did not persist, however, when the results were analysed for WCBs and other tradesmen separately.

The 207 leavers who were reassessed had on average left the shipyard $4 \cdot 0$ (rarige $0 \cdot 7-8 \cdot 0$ ) years previously. Most of them were in employment $(84.5 \%)$ but of the 136 men who had been WCBs only 11 were doing comparable work in other shipyards and 42 were following their trade in other industries. Thus at the time of reassessment, 83 WCBs had had no recent fume exposure.

Three hundred and forty six men were followed up, of whom 148 were classified as smokers and 198 as non-smokers. At their initial examination, 21 of these men had reported chronic cough and phlegm and 107 men had reported wheeze. Subsequently, some men developed symptoms whereas others lost one or more symptoms. The risk of acquiring symptoms was enhanced by being a smoker or being exposed to fumes as a WCB (table 4). The association with trade was not seen among the subgroup of men who continued to work in the shipyard. These men experienced a significant reduction in the prevalence of wheeze, independently of their trade.

\section{Lung function at follow up analysed cross sectionally}

After standardisation for age and stature, no differences in lung function were found between other tradesmen who remained in the yard and all men who had left, whether or not they were smokers. The lung function of these men was now in many respects superior to that of WCBs who remained in the yard. By contrast, at the initial assessment for the same workers and with the same type of analysis, the lung function of the welders who were to remain did not differ from that of the other subjects (table 5). A nearly identical result was obtained when the analysis was confined to WCBs and when allowance was also made for smoking habits. Atopy was associated with a reduced slope of phase III of the single breath nitrogen test in WCBs compared with other tradesmen. Atopy did not contribute to the description of the other indices of lung function. 
Table 5 Lung function standardised for age and stature for WVCBs who continued to work in the shipyard (active WCBs) compared with all others who were followed up

\begin{tabular}{|c|c|c|c|c|}
\hline & \multicolumn{2}{|c|}{ Mean results at follow up } & \multicolumn{2}{|c|}{ Mean initial results } \\
\hline & $\begin{array}{l}\text { Active } \\
W C B s\end{array}$ & $\begin{array}{l}\text { All } \\
\text { others }\end{array}$ & $\begin{array}{c}\text { Active } \\
\text { WCBs }\end{array}$ & $\begin{array}{l}\text { All } \\
\text { others }\end{array}$ \\
\hline $\begin{array}{l}\text { FEV }_{1}(1) \\
\text { PEF }\left(\mathbf{l ~ s}^{-1}\right) \\
\text { RV\% }_{\text {(of TLC) }} \\
\text { MTT }_{97 \approx \text { rNC (s) }}\end{array}$ & $\begin{array}{c}4 \cdot 20 \\
10 \cdot 00 \\
20 \cdot 2 \\
0.78\end{array}$ & $\begin{array}{c}4 \cdot 36^{\star} \\
10 \cdot 47^{\star} \\
19 \cdot 2^{\star} \\
0 \cdot 71^{\star}\end{array}$ & $\begin{array}{c}4 \cdot 33 \\
9 \cdot 97 \\
18 \cdot 3 \\
0 \cdot 60\end{array}$ & $\begin{array}{c}4.41 \mathrm{NS} \\
10.10 \mathrm{NS} \\
17.1 \mathrm{NS} \\
0.59 \mathrm{NS}\end{array}$ \\
\hline
\end{tabular}

\section{Longitudinal changes in lung function}

Overall changes; roles of age and of anthropometric factors-Over the period of follow up the $\mathrm{FEV}_{1}$ declined by on average $11.1 \mathrm{ml} \mathrm{y}^{-1}$ and Tl' by $0.11 \mathrm{mmol} \mathrm{min} \mathrm{mat}^{-1} \mathrm{kPa}^{-1} \mathrm{y}^{-1}$. The PEF increased by $35.1 \mathrm{ml} \mathrm{s}^{-1} \mathrm{y}^{-1}$ and the total lung capacity by $16.4 \mathrm{ml} \mathrm{y}^{-1}$. These and the other changes in lung function (table 1) were associated with and to some extent due to increases in stature and body mass and composition (see analysis); table 6 indicates the contributions of anthropometric factors to the changes in lung function. After allowing for growth, the annual changes in all the principal indices of lung function, but not the ratio indices (for example, $\mathrm{FEV}_{1 \%}$ ), were correlated with mean age (as defined in analysis). Except in the case of $\mathrm{FEF}_{75-85 \%}$ (where bias occurred on account of concurrent changes in vital capacity with age), the effect of increasing age was always deleterious.

Relevence of atopy-Atopy in smokers was associated with impaired airway function as assessed by $\triangle \mathrm{FEV}_{1 \%}, \triangle \mathrm{MEF}_{25 \% \mathrm{FvC}}, \triangle \mathrm{FET}$, and changes in the mean and dispersions of transit times for blows truncated at $99 \%$ of VC. Atopy interacted with trade to reduce the F/V area ratio and, if men from cohort 2 were included, with smoking and trade to increase the airway obstruction index. ${ }^{14}$ For most of these indices the variance attributable to atopy in smokers (Sm.atopy) was less than that associated with continued work as a WCB (T.SY). For example in the case of $\triangle \mathrm{FEV}_{1 \%}, 2 \cdot 4 \%$ of the variance was accounted for by SM.atopy compared with $4.8 \%$ by T.SY. Thus the effects of atopy were confined to smokers and seemed to be peripheral to the

Table 6 Regression equations in which trade as WCBs $(T)$ or continuing to work in the shipyards $(S Y)$ contributed to description of changes in lung function over the period of follow up.

\begin{tabular}{|c|c|}
\hline 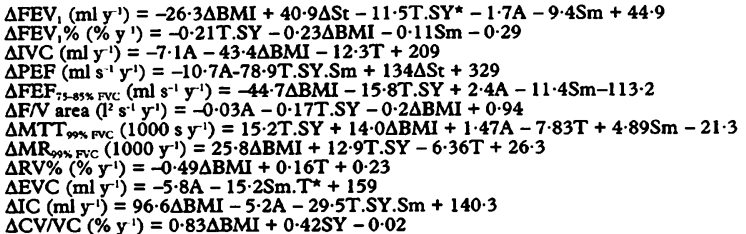 & $\begin{array}{l}(0.13) \\
(0.08) \\
(0.25) \\
(0.11) \\
(0.12) \\
(0.08) \\
(0 \cdot 18) \\
(0.14) \\
(0.08) \\
(0 \cdot 18) \\
(0.28) \\
(0.19)\end{array}$ \\
\hline
\end{tabular}

Terms are given in the order of their contributions to the explained variance; the sum of the con tributions-that is, the proportion of variance explained by the regression-are in parentheses; the numbers of subjects for the different tests are given in table 1 .

Occupation did not contribute to the descriptions of $\triangle F V C, \triangle T L C, \triangle F R C, \triangle R V, \Delta$ transfer factor, $\Delta \mathrm{KcO}$, or $\Delta$ slope III of the single breath nitrogen test.

*Term only of borderline significance $(\mathrm{P}=0 \cdot 11$ ) when component terms (not themselves significant) were forced into the regression. objectives of the present study. Atopy was not included in the final analysis.

Smoking and trade as a WCB-Among the follow up population, continuing to smoke ( $\mathrm{Sm}$ in table 6) had an adverse effect on the

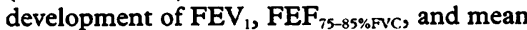
transit time. These effects were independent of those of shipyard trade. In other instances smoking was detrimental in association with exposure to shipyard fumes. Trade $(T)$ as a WCB, independently of whether or not a man had left the shipyard, was associated with adverse changes in inspiratory vital capacity and residual volume ( $\triangle \mathrm{IVC}, \Delta \mathrm{RV} \%$ ); there were beneficial changes in mean transit time $\left(\mathrm{MTT}_{99 \% \mathrm{FvC}}\right)$ and moment ratio $\left(\mathrm{MR}_{99 \% \mathrm{FvC}}\right)$. (For WCBs who continued in the shipyard, the relative improvements in these indices were more than offset by deterioration associated with continued exposure to shipyard fumes.) Smoking apparently interacted with shipyard trade to impair the development of expiratory vital capacity ( $\triangle E V C$ ). Continued shipyard work as a WCB was associated wth enhanced deterioration in $\mathrm{FEV}_{1}, \mathrm{FEF}_{75-85 \%}$, $\mathrm{F} / \mathrm{N}$ area, and mean transit time and moment ratio (T.SY significant in table 6 ). There was also enhanced deterioration of PEF and inspiratory capacity, but for these indices the additional deterioration was confined to smokers (T.SY.Sm significant in table 6). Figures 1 and 2 illustrate the average effects of smoking and of occupational history on the evolution of $\mathrm{FEV}_{1}$ and PEF in a hypothetical shipyard worker. The indices for which the annual changes were independent of trade, smoking, or work in the shipyard included FVC, transfer factor, $\mathrm{KCO}$, total lung capacity, functional residual capacity and nitrogen slope.

For the 198 men who did not smoke during the period of follow up, the changes in lung function associated with trade and with continued work in the shipyard were essentially the same as in the whole group (figs 1 and 2).

Reported use of exhaust ventilationInformation as to whether or not exhaust ventilation was used $100 \%$ of the time was obtained at follow up on 100 welders in cohort 1 and 109 welders in cohort 2. For both cohorts together 115 men (55\%) reported regular use. The decline in $\mathrm{FEV}_{1}$ experienced by these men was smaller by 16 $\mathrm{ml} \mathrm{y}^{-1}$ compared with those who were less punctilious. (For the two cohorts separately, the improvement was significant in cohort 2 and nearly significant in cohort $1(p=$ $0.065)$.) The beneficial effect of regular use was also evident among the subgroup of men who left the yard before follow up $(n=127)$. Among the subgroup who remained some benefit may have occurred, but it did not reach statistical significance $(p=0.093)$. Regular use of exhaust ventilation improved the development of PEF in those welders who were smokers.

\section{Discussion}

Since the dawn of history the techniques for building ships have been in a state of 
Figure 1 Evolution of $F E V$, in young shipyard workers from the equation (assuming an initial FEV, at age 18 of $4.4 \mathrm{l}$ and no subsequent changes in stature or body composition). workers from the equatio

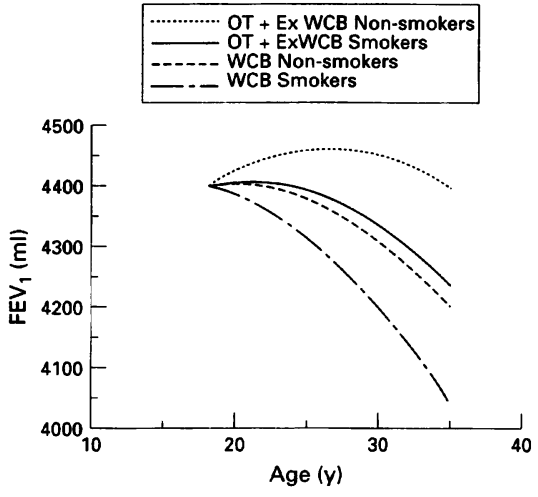

evolution and the changes did not stop with the introduction in the 1930s of welding for joining sheets of mild steel. Within the lifetime of some current welders the changes have included the withdrawal of asbestos from welding rods, the elimination of potentially harmful surface treatments for steel plate, changes in the composition of steel, the use of new fluxes and different forms of local exhaust ventilation at the site of the weld, and techniques of various types for screening off the men from the gases which are produced. These changes have altered the nature of the fumes and the quantity which reaches the lungs. Also, the susceptibility of the workforce could have been modified by changes in atmospheric air pollution, alterations in smoking habits, and the composition of tobacco smoke and alterations in the criteria used for selecting apprentice welders. On account of these changes previous studies of the mortality and morbidity of welders, including studies of lung function, are unlikely to be relevant for welders entering the industry today. No study can be up to date, however, as during the time between an exposure and its effects becoming manifest the technology is likely to have changed further. Also, the appraisal of the effect is seldom instantaneous. For assessing chronic changes in lung function a follow up period of five to seven years is usually considered optimal. ${ }^{18}$

Figure 2 Evolution of PEF in young shipyard workers from the equation for $\triangle P E F$ in table 6 (assuming an initial PEF at age 18 of $10 \mathrm{ls}^{-1}$ and no subsequent changes in stature or body composition).
In the present study the time scale was expanded by delays which arose both directly from the rationalisation of the shipbuilding industry in the United Kingdom that occurred in the 1980 s and indirectly from their secondary consequences. These delays extended the study to over 11 years. This time could have affected the comparability of the initial and final measurements. Any such differences were minimised by one observer (DJC) being responsible for both sets of measurements, by careful choice and calibration of replacement items of equipment, and by rigorous adherence to experimental protocols. The effectiveness of these procedures in securing results that were internally consistent was assessed from the findings for 56 of the men who were seen on three occasions, the first about three years before they were included in the present study. For these subjects two estimates of the annual change in FEV, and FVC were available, one from the first and second examinations, the other from the second and third examinations. The mean differences in these two estimates with their standard errors were respectively -0.0046 $(0.011) 1 \mathrm{y}^{-1}$ and $-0.0097(0.013) 1 \mathrm{y}^{-1}$ (fig 3). Also, the WCBs and other tradesmen were seen concurrently so, if there had been any longitudinal trends in the measurements these would not have biased the principal comparison.

Bias could have occurred by selective recruitment to the different trades; it could also have occurred between those who remained in the yard or were made redundant or left for other reasons and, among the

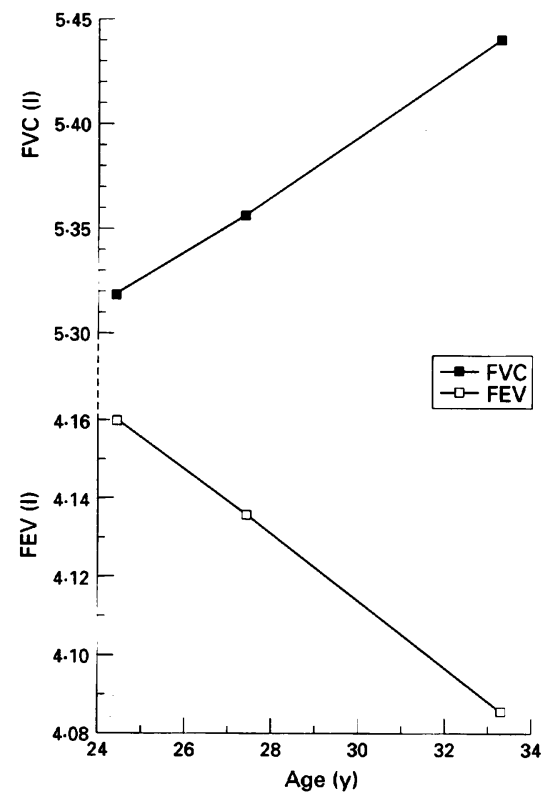

Figure 3 Mean values for FEV and FVC in 56 men who were assessed on three occasions. The first assessment was about three years before they were included in the present study. 
leavers, between those who were reassessed and the men who eluded follow up. ${ }^{19}$ In the event the only selection at entry was self selection as the same medical criteria were applied to all apprentices independent of trade. The leavers included a higher proportion of WCBs than of other tradesmen and more of the men with respiratory symptoms. Among the leavers the lapses similarly included more WCBs, more smokers, and more of the men with symptoms. Thus to some extent the bias introduced by the retention in the yard of relatively asymptomatic workers was mirrored by the follow up being similarly biased in favour of the more asymptomatic leavers. Possibly for this reason the initial results for dynamic spirometry and lung volumes were consistent between the several groups. A different pattern was found for transfer factor, which was significantly better in the leavers who were reassessed compared with the lapses. When subdivided by trade, however, the mean transfer factor standardised for age and stature, for the lapses amongst the WCBs was not significantly different from that for the WCBs who were followed up (respectively 11.97 and $\left.12.05 \mathrm{mmol} \mathrm{min} \mathrm{m}^{-1} \mathrm{kPa}^{-1}\right)$. There was a similar pattern for the other tradesmen. Thus the possible selection bias with respect to respiratory symptoms did not extend to the initial lung function.

The hypothesis that selection bias on account of symptoms could have influenced the decline in lung function was tested by extending the analysis of $\triangle F E_{1}$ and $\triangle P E F$ (table 6) to also include symptoms; the men with symptoms experienced an enhanced deterioration, but the association was independent of trade. Thus whereas bias due to selection factors could not be ruled out its occurrence seems unlikely to have contributed to the differences in lung function between the WCBs and other tradesmen.

The present workers in cohort 1 were selected on account of their youth and of having only worked in the industry after the introduction of exhaust ventilation and other hygiene measures. After 1978 the working environment was subject to continuous monitoring, which mostly indicated good standards of control where exhaust ventilation was used correctly. Thus it was not expected that the men's respiratory systems at the time of entry to the study would have been materially affected by industrial fumes. In the event, the prevalence of respiratory symptoms was influenced by the WCBs including a higher proportion of smokers than the other tradesmen. Also, both in non-smokers and in smokers stratified by the amount smoked, trade as a WCB was independently associated with increased chronic cough, phlegm, and wheeze. Overall, the WCBs who smoked had a disproportionately increased prevalence of chronic cough. The occurrence of symptoms was associated with a greater degree of airflow limitation compared with that attributable to smoking and trade. On entry to the study and independent of smoking, however, trade as a WCB was associated with a relatively low peak expiratory flow and other evidence of mild respiratory impairment; among subjects with a normal $\mathrm{FEV}_{1} \%$, the welders who were also smokers exhibited an extended mean transit time. Thus at the time of admission to the study the WCBs already exhibited minor respiratory impairment compared with the other tradesmen. This was probably due to exposure to fumes, and not to differences introduced at initial recruitment to the yard, ${ }^{2}$ or to selection for study of other tradesmen with above average respiratory health; however, the proportion of refusals among the electricians was not recorded.

The longitudinal analysis was complicated by several factors: these included the high levels of redundancy and the loss to follow up of men who left the industry and subsequently moved away from the area. The possible effects of these factors have been discussed earlier. A proportion of WCBs continued their trade outside the shipbuilding industry. They were classified as WCBs no longer in the słipyard (hence for the analysis summarised in table $6, T=0$ ), as in such circumstances only very minor lung damage can be attributed to welding fumes. ${ }^{2021}$ Any effect from such exposures would have been in the direction of underestimation of both the damage to the lungs from shipyard welding, and the improvement from giving it up.

Many men changed their smoking habits more than once during the period of follow up. This was allowed for by defining as a smoker anyone who was smoking at any time during the period of follow up. Men who were ex-smokers throughout were included with the non-smokers. Some men who were made redundant seemed to vegetate and put on weight whereas others took up physical exercise, sport, or weight training. Any of these activities could have led to changes in fat and muscle and in consequence might have influenced lung function ${ }^{1322}$; the changes were allowed for by including in the initial analysis separate terms for changes in body fat and muscle. The use of these terms, however, did not materially increase the proportion of variance explained by the regressions compared with $\triangle \mathrm{BMI}$.

The study was made over the period in life when lung function is normally in transition from improving as a result of physical growth and maturation to deteriorating due to exposure to tobacco smoke, wear and tear, and other components of ageing. ${ }^{2324}$ These factors affect the different lung function indices in sequence so that for most of the present workers the FEV was deteriorating throughout the period of observation $\left(\triangle F E V_{1}\right.$ negative in table 1) whereas FVC and PEF were increasing ( $\triangle F V C$ and $\triangle P E F$ on average positive). With few exceptions, increasing age exerted a deleterious effect; this was represented by a positive coefficient on age in the equation describing $\Delta M T T_{99 \%, F c}($ table 6), and a negative coefficient for most other indices. Hence for most indices, the relation of change in lung function to age was curvilinear (see figs). The effects of smoking, trade, and work in the 
shipyard were superimposed on these basic patterns.

Over the period of follow up the likelihood of developing respiratory symptoms was mainly linked to smoking, but trade as WCBs influenced the onset of productive cough. The analysis of factors associated with loss of symptoms was weak on account of the small numbers of men who both initially had chronic cough and or phlegm and were followed up. The numbers were greater for wheeze and here continuing to work in the shipyard had a favourable influence: this paradox was probably due to self selection but a contributory factor could have been a progressive improvement in the working environment over the period of the study.

The longitudinal changes in lung function showed a less ambiguous pattern. Welders and caulker/burners who continued to work in the shipyard on average exhibited evidence for additional narrowing of all classes of airway compared with other tradesmen or WCBs who left the shipbuilding industry. For indices that are believed to mainly reflect the calibre of medium and small airways including $\triangle F V_{1}, \triangle F F_{75-85 \% F C}$, and changes in transit time indices, $\Delta F / V$ area, the fume related narrowing was independent of smoking. For welders in the shipyard protection was provided by exhaust ventilation when it was used $100 \%$ of the time. For PEF, which is influenced by the calibre of the larger airways, and also the inspiratory capacity, the adverse effect on WCBs was apparently confined to the smokers; $100 \%$ use of exhaust ventilation did not provide protection. This result was obtained in the relatively asymptomatic WCBs who continued to work in the shipyard. No evidence was obtained to support the hypothesis that the more symptomatic men who left the industry might have fared worse had they remained but, as pointed out earlier, any error would have been in the direction of underestimating the effect of continued work as WCBs.

On leaving the industry the more symptomatic WCBs who left seemed not to lose their symptoms. With the exception of $\triangle F E V_{1}$ and $\triangle F V C$ in leavers who had previously defaulted on their exhaust ventilation, the lung function improved compared with their peers who remained in the industry. On average, by the end of the period of follow up lung function was on a par with that of the other tradesmen (table 5). This result is different from that of the older ex-WCBs studied previously whose lung function continued to deteriorate ${ }^{4}$ but to what extent the difference reflected the duration or the intensity of the exposure could not be determined. The longitudinal results for the 181 men in cohort 2 whose initial ages (29-47 years) were intermediate between those for the men in the present and the previous studies suggested that in their case the adverse effects of WCBs were in some respects irreversible (unpublished data). Thus as with smoking, there is probably a continuum of effect to which both duration and intensity contribute. In the case of the present smokers, atopy also seemed to be important but the evidence for atopy contributing to the changes associated with WCBs was insubstantial. It was slightly stronger when results for cohorts 1 and 2 were combined. Then on cross sectional analysis, the atopic WCBs who remained in the yard had a reduced $F E V_{1}$ and $P E F$ compared with other tradesmen in the yard. Whereas the difference was seen for both the initial and final results separately the longitudinal changes were, however, mainly independent of atopy. This result differed from that obtained previously for older men. ${ }^{4}$ The reason is unclear but it could be related to the high prevalence of atopy among cohort 1 and to the present but not the previous result for WCBs being largely independent of that of smoking.

The relative magnitudes of the effects of work as WCBs and of smoking are contained in their respective contributions to the total variance explained by the multiple regression equations and in the size of the relevant parameters. These features can be comparêd directly from those indices where both effects were present without there being significant interaction between them; the relevant indices were $\Delta \mathrm{FEV}_{1}, \Delta \mathrm{FEF}_{75-85 \%}$, and $\triangle \mathrm{MTT}_{99 \% \mathrm{Fvc}}$ (table 6 and fig 1). For all these indices the term T.SY accounted for rather more of the variance than the term $\mathrm{Sm}$, and the associated coefficients were significantly larger. Similarly amongst WCBs, the average change in $\triangle \mathrm{PEF}$ associated with smoking was less than the change associated with discontinuing work in the shipyard (fig 4). Thus on average, exposure to fumes for WCBs during a working week was at least as harmful to the lung airways as smoking 18.6 cigarettes per day.

\section{Conclusions and implications}

In the present study of shipyard workers who were predominantly in the $20-30$ year age

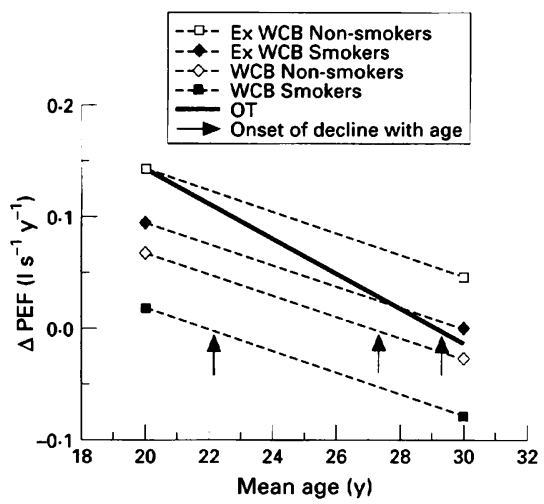

Figure 4 Annual change in PEF in young shipyard WCBs showing the effect of employment and smoking 20 cigarettes/day, based on the equation:

$\triangle P E F$ in $W C B=8.944 S t-0.013 A-0.021 T$.SY $-0.0015 T c / d+0.389$

where $T c / d$ is tobacco consumption/day (g). 
group, work as a WCB was associated with excess respiratory symptoms and with changes in lung function suggestive of narrowing of all classes of airways. The effects were largely independent of smoking. They were equivalent to smoking an average of 18.6 cigarettes per day and for the caulker/burners, were reversed after discontinuing exposure. Among welders the effect of the fumes was greatest in those who admitted to not using their exhaust ventilation at all times; such men experienced a work related deterioration in $\mathrm{FEV}_{1}$, which did not improve during the period of follow up (on average 4.0 years) after leaving the shipyard. For regular users who continued in the shipyard, the present levels of respiratory protection were probably effective in reducing or even eliminating the respiratory effects of welding fumes on $\mathrm{FEV}_{1}$; however the confidence limits of the estimates were too wide for accurate estimation of any residual impairment. The protection provided by exhaust ventilation was less complete when assessed in terms of PEF, but again the changes were reversible, unlike in the intermittent users of exhaust ventilation, among whom there was no evidence for full recovery. The shipyard welders had been required to use personally directed local exhaust ventilation throughout their employment, although its regular use did not of itself guarantee that the exhaust hose was placed in the optimal position or that the suction was adequate; indeed some men volunteered that these features were suboptimal. The results of the hygiene monitoring and related findings were reported as indicating that the environmental control usually conformed to the current occupational exposure standards when the equipment was used correctly. In the absence of exposure data for individual men the adequacy of the standards could not be assessed. The present results showed a need for stricter application of existing measures for controlling fumes, and accurate monitoring of respiratory symptoms and function to establish whether or not the control was adequate. In addition, further attempts should be made to discourage smoking. The monitoring should be by questionnaire and longitudinal measurement of both FEV and PEF as these indices measure different aspects of the response. Other indices from the $F / V$ curve and the transit time analysis of spirograms provided mainly confirmatory information whereas transfer factor and most of the lung volume measurements were uninformative. For the purposes of monitoring, the equipment should be calibrated regularly and the technicians should have been trained to the high technical standards required for longitudinal studies.
The study was made possible through the collaboration of all levels of management, the staff of the shipyard medical centre, and the work force at the shipyard. The funding came from many sources including the Medical Research Council, the Health and Safety Executive, and recently the Wellcom Trust. The University of Newcastle upon Tyne kindly provided facilities. Many colleagues contributed to the measurements including Mrs J Askew, Miss NG Bridges measurements including Mrs J Askew, Miss NG Bridges (now D Goodwin), Mr IS Davey, Mr C Elliott, Miss R Harkawat, Mr AM Marks, Dr JW Reed, Mr IC Stevenson, and research students. Mr TGE Gillanders supervised the hygiene measure ments. Mr R Scott (University Department of Medical Physics) contributed to the transit time analyses. Mrs AB Blackhall typed the manuscript. Previously JF Wollaston wa Director of Health and Safety and Chief Medical Officer British Shipbuilders.

1 Newhouse ML, Oakes D, Woolley AJ. Mortality of welders and other craftsmen at a shipyard in NE England. $\mathrm{Br} f$ Ind Med 1985;42:406-10.

2 Cotes JE, Feinmann EL, Male VJ, Rennie FS, Whickham CAC. Respiratory symptoms and impairment in ship yard welders and caulker/burners. $B r \mathcal{F}$ Ind Med 1989 46:292-301.

3 Newhouse Mi, Murray R. The present position concerning the biological effects of exposure to fume in welders. Abingto Hall, Cambridge: Welding Institute, 1979. (Publ No 5510/46/79)

4 Chinn DJ, Stevenson IC, Cotes JE. Longitudinal respiratory survey of shipyard workers: effects of trade and atopic status. Br f Ind Med 1990;47:83-90.

5 Weller J, El-Gamal FM, Parker L, Reed JW, Cotes JE. Indirect estimation of maximal oxygen uptake for study Indirect estimation of maximal oxygen uptake for stud
of working populations. $\mathrm{Br} \mathcal{Y}$ Ind Med 1988;45:532-7.

6 Field GB. The application of a quantitative estimlate of cough frequency to epidemiological surveys. Int $f$ Epidemiol 1974;3:135-43.

7 Weiner JS, Lourie JA, eds. Practical human biology London: Academic Press, 1981

8 Durnin JVGA, Rahaman MM. The assessment of the amount of fat in the human body from measurements of skinfold thickness. Br $\mathcal{F}$ Nutr 1967;21:681-9.

9 McDermott M, McDermott TJ. Digital incremental tech niques applied to spirometry. Proceedings of the Royal Society of Medicine 1977;70:169-71.

10 Quanjer $\mathrm{PhH}$, ed. Standardized lung function testing. Bulletin Européen de Physiopathologie Respiratoire 1983;19 (suppl 5):1-95.

11 Chinn DJ, Cotes JE. Transit time indices derived from forced expiratory spirograms: repeatability and criteria for curve selection and truncation. Eur Respir $f 1994$ 7:402-8.

12 Chinn DJ, Naruse Y, Cotes JE. Accuracy of gas analysis in lung function laboratories. Thorax 1986;41:133-7.

13 Cotes JE. Lung function: assessment and application in medicine, Sth ed. Oxford: Blackwell, 1993.

14 Cotes JE. Lung volume indices of airway obstruction: a suggestion for a new combined index. Proceedings of the Royal Society of Medicine 1971;64:1232-4.

15 Craven N, Sidwall G, West P, McCarthy DS, Cherniack RM. Computer analysis of the single-breath washout curve. Am Rev Respir Dis 1976;113:445-9.

16 National Heart and Lung Institute. Suggested standardized procedures for closing volume determinations (nitrogen method). Bethesda, MD: National Heart and Lung Institute, 1973.

17 Health and Safety Executive (HSE). Substances hazardous to health. Occupational exposure limits. Exposure limits for chemical substances in workplace air. London; HSE, 1986. (Guidance note EH 40.)

18 Berry G. Longitudinal observations. Their usefulness and limitations with special reference to the forced expiratory volume. Bulletin Européen de Physiopathologie Respiratoire volume. Bulletin

19 Cotes JE, Chinn DJ. Is respiratory function deminished? In: Landrigan PJ, Kazemi $\mathrm{H}$, eds. The third wave of In: Landrigan PJ, Kazemi $\mathrm{H}$, eds. The third wave of
asbestos disease: exposure to asbestos in place. Ann NY asbestos disease: exposure to

20 Cotes JE, Steel J. Work-related lung disorders. Oxford Blackwell 1987.

21 Sferlazza SJ, Beckett WS. The respiratory health of welders. Am Rev Respir Dis 1991;143:1134-48.

22 Cotes JE, Gilson JC. Effect of inactivity, weight gain and antitubercular chemotherapy upon lung function in working coal-miners. Ann Occup Hyg 1967;10:327-35.

23 Hurwitz S, Allen J, Liben A, Becklake MR. Lung function in young adults: evidence for differences in the chronological age at which various functions start to decline. Thorax 1980;35:615-9.

24 Becklake MR. Occupational exposures. Evidence for a causal association with chronic obstructive pulmonary disease. Am Rev Respir Dis 1989;140:S85-91. 